\title{
EFFECT OF MATERIAL ON THE MECHANICAL PROPERTIES OF ADDITIVE MANUFACTURED THERMOPLASTIC PARTS
}

\author{
D. K. K. Cavalcanti, M. D. Banea*, H. F. M. de Queiroz \\ Federal Center of Technological Education in Rio de Janeiro, Brazil \\ *Corresponding author's e-mail address: $\underline{\text { mdbanea@gmail.com }}$
}

\begin{abstract}
Additive manufacturing ( $A M)$ also called $3 D$ printing, is an emerging process in the manufacturing sector with increasing new applications in aerospace, prototyping, medical devices and product development, among others. The resistance of the AM part is determined by the chosen material and the printing parameters. As novel materials and AM methods are continuously being developed, there is a need for the development and mechanical characterization of suitable materials for $3 D$ printing. In this study, the influence of the material and the 3D-printing parameters on the mechanical properties of additive manufactured thermoplastic parts was investigated. Three different filaments that are commercially available: Polylactic acid (PLA), acrylonitrile butadiene styrene (ABS) and Tritan were used. Tensile and flexural tests were carried out, in accordance to ASTM standards, to investigate and compare the mechanical properties of the AM parts as a function of material used. The results showed that the type of filaments had the greatest influence on the mechanical properties of the AM parts. The maximum strength and stiffness were obtained for the PLA specimens. Tritan displayed the highest deformation, while the PLA manifested the lowest deformation capacity. The mechanical properties of the printed parts also depend on the printing parameters. The parameters used in this work are a good compromise between the printing time and the mechanical properties.
\end{abstract}

KEYWORDS: Additive manufactured parts, PLA, ABS, Tritan, Mechanical properties.

\section{INTRODUCTION}

Additive manufacturing (3D printing technology) is a process in which 3D components, with high precision and complexity, are made by depositing materials in a layer-by-layer fashion, as opposed to conventional machining or forming methods [1]. One of the most common methods for 3D printing of polymeric materials is the Fused Filament Fabrication (FFF) or Fused Deposition Modelling (FDM) technique [2].

The resistance of the AM part is determined by the chosen material and printing parameters [3], [4]. Therefore, using the correct process parameters for the FDM technique is essential to ensure that the material can be printed with a good surface finish and high precision. These process parameters are: the layer thickness, raster orientation and infill density, build orientation, printing temperature and speed. Each parameter may have different settings for different materials, depending on their flow properties [5]. For example, the mechanical properties of 3D printed parts seem to be strongly dependent on the printing orientation (i.e. the tensile strength of FDM printed samples printed in the $\mathrm{XYZ}$ direction can be 5 times higher than those printed vertically). Sood et. al. [6] showed that the mechanical properties of the AM parts are related to the number of printed layers. This is due to the thermal cycles (heating and cooling) that will cause cumulative residual stresses, distortion, interlayer cracking and delamination.

The nature of the AM technique limits the choice of materials. The majority of the materials used for AM are thermoplastics (i.e. Polylactic Acid (PLA) and Acrylonitrile Butadiene Styrene (ABS)). PLA is a linear aliphatic thermoplastic polyester, produced from renewable biodegradable materials. PLA has excellent mechanical properties, thermal stability, good processing capability, and low environmental impact. However, one disadvantage is that PLA is relatively expensive as compared to other petroleum-based polymers [7]. The ABS thermoplastic material has good mechanical properties, but it emits an unpleasant odour during processing [5]. However, novel materials for 3D printing are continuously being developed. Thus, in order to further understand the mechanical properties of these AM materials and stimulate their use in new applications in the industry, more research work is needed.

The main objective of this work was to characterise three different filament materials that are commercially

(C) Galati University Press, 2020

Date of submission/acceptance: $31.05 .2020 / 15.12 .2020$

https://doi.org/10.35219/awet.2020.01 
available in order to understand the mechanical behaviour of $3 \mathrm{D}$ printed materials and to stimulate their use in new applications.

\section{MATERIALS AND METHODS}

\subsection{Materials}

All the materials used in this work were provided by GTMax3D (Americana, SP, Brazil) under the form of filaments. The basic mechanical properties as per supplier can be seen in table 1. The PLA and ABS thermoplastic materials are well known in the industry. Tritan is an amorphous copolyester, a modified polyester with diacids and diols), that offers some advantages, such as: clarity, toughness, heat resistance, chemical resistance, resulting in more robust parts in the context of $3 \mathrm{D}$ printing.

Table 1. Mechanical properties of the materials

\begin{tabular}{|c|c|c|c|}
\hline Material & $\begin{array}{c}\text { Tensile } \\
\text { strength } \\
{[\mathbf{M P a}]}\end{array}$ & $\begin{array}{c}\text { Flexural } \\
\text { modulus } \\
{[\mathbf{G P a}]}\end{array}$ & $\begin{array}{c}\text { Tensile } \\
\text { strain } \\
{[\%]}\end{array}$ \\
\hline PLA & 53 & 3.50 & 6 \\
ABS & 29 & 0.26 & 18 \\
Tritan & 43 & 1.55 & 210 \\
\hline
\end{tabular}

\subsection{Specimens Manufacture}

The AM specimens were manufactured using a Core A1v2 3D printer form GTMax3D (Americana, SP, Brazil). The printing process parameters used in this work are included in table 2 and were chosen based on the literature and some in-house laboratory trials. The layer height was $0.3 \mathrm{~mm}$ as it was shown in the literature that treated the best mechanical properties and shorter production times for FDM 3D printing [8].

Table 2. Printing parameters used for all specimens

\begin{tabular}{|l|c|}
\hline Printing Parameters & Value \\
\hline Nozzle diameter [mm] & 0.40 \\
Layer height [mm] & 0.30 \\
Raster width [mm] & 0.44 \\
Raster angle & $0^{\circ}$ \\
Infill [\%] & 100 \\
Extruder temperature $\left[\mathrm{C}^{\circ}\right]$ & 250 \\
Printing bed temperature $\left[\mathrm{C}^{\circ}\right]$ & 120 \\
Printing speed [mm $/ \mathrm{s}]$ & 45 \\
Number of contours & 44 \\
\hline
\end{tabular}

The raster width chosen was $0.44 \mathrm{~mm}$, since this will reduce internal voids (Fig. 1) occurring by raster overlapping [9]. The raster angle chosen was $0^{\circ}$, as it was shown in the literature that a raster angle of $0^{\circ}$ is the optimum direction of depositions if high tensile strength is desired. The infill chosen was $100 \%$, since the properties of printed parts are associated to internal voids [8]. The printing speed used was $45 \mathrm{~mm} / \mathrm{s}$ as it was shown in the literature this printing speed yields the best results by providing increased diffusion, larger interfacial width and lower internal voids. The slower speed also permits a longer exposure to heat, increasing the diffusion between the rasters and layers [10]. Finally, the extruder and bed temperature values used were chosen based on the fact that the temperature has a significant impact in the part's properties. A continuous increase in material properties was observed as the nozzle temperature increased, while the bed temperature (i.e. $120^{\circ} \mathrm{C}$ ) was chosen to reduce a possible temperature gradient between the top and bottom layers [11].

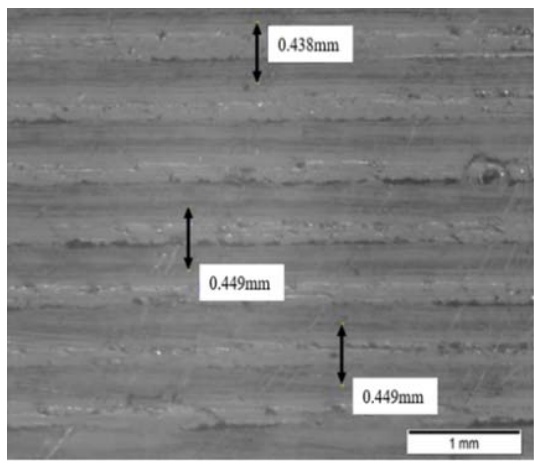

Fig. 1. Magnification of printed ABS core with indications of raster width (contrast was performed using graphite powder)

Slicing was performed with Simplify $3 \mathrm{D}^{\circledR}$ and all test specimens were manufactured in a flat-edge orientation as shown in figure 2 . The number of contours was high enough to ensure that the raster angle was $0^{\circ}$ (Fig. 3). The configuration used is independent on the XY build orientation.

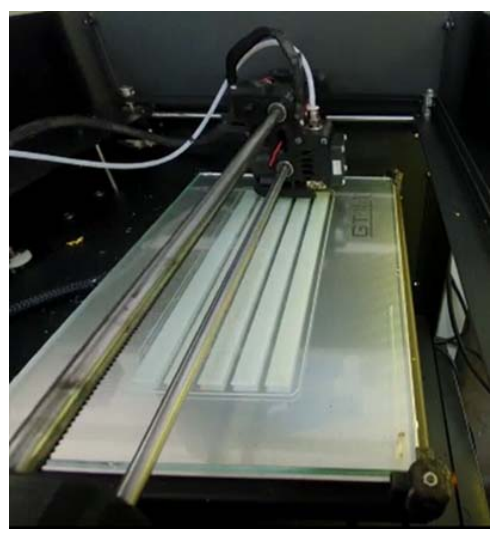

Fig. 2. 3D printing process fabrication of $A M$ specimens 
a)

b)

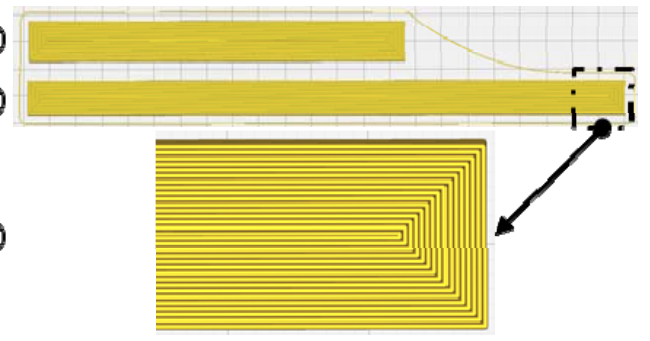

Fig. 3. Preview of the specimens and their layering after slicing (from the Simplify $3 \mathrm{D}^{\circledR}$ ): a) flexural; b)

tensile; c) magnification of specimen surface

The specimen dimensions (in $\mathrm{mm}$ ) can be seen in figure 4. As there are no recognized standards in the literature for the quantification of the mechanical properties of FDM parts, the specimen dimensions of the tensile specimens were chosen after in-house laboratory experimentation (the configuration chosen showed consistent failure within the specimen width of the tab or grip).

a)

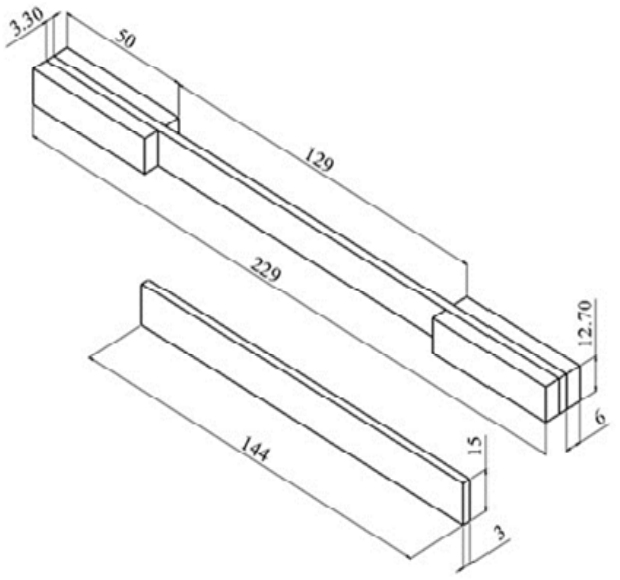

Fig. 4. Scheme of AM part specimens: a) tensile; b) flexural

\subsection{Test Method}

The tensile and flexural tests were performed at room temperature by means of an INSTRON ${ }^{\circledR}$ model 5966 testing machine (Norwood, Massachusetts, USA). The tensile tests were carried out with a cross head speed of $2 \mathrm{~mm} / \mathrm{min}$ and a load cell of $10 \mathrm{kN}$. A strain gauge extensometer was used to record the strain, as seen in figure 5. A $50 \times 15 \times 6 \mathrm{~mm}$ tab was used on either side or extremity of the specimen in order to ensure that all failures occurred in the proper area.

For the flexural tests a three-point bending rig with a span of $120 \mathrm{~mm}$, cross head speed of 1 $\mathrm{mm} / \mathrm{min}$ and a $1 \mathrm{kN}$ load cell were used, as per ASTM D790 standard. Four specimens were tested for each condition.

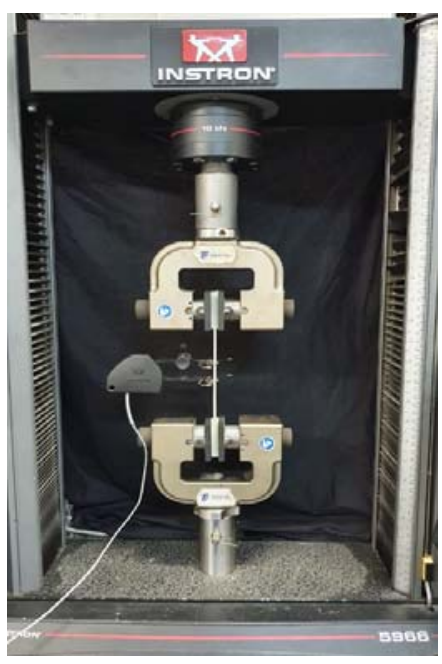

Fig. 5. Tensile test set-up

\subsection{Preliminary Parametric Study}

Prior to the mechanical tests, a preliminary study was performed in order to verify if the printing temperature chosen (i.e. $250{ }^{\circ} \mathrm{C}$ ) is adequate for printing the Tritan material as this temperature is lower than the minimum temperature recommended by the supplier (i.e. $260{ }^{\circ} \mathrm{C}$ ). Therefore, the Tritan was also printed with an extruder temperature of $280{ }^{\circ} \mathrm{C}$. All other parameters are kept the same (Table 2). Representative stress-strain curves for the two cases studied are shown in figure 6. From these curves the tensile properties were calculated, and it was found that the difference between the tensile strength of the samples printed at $250^{\circ} \mathrm{C}$ (i.e. $37.79 \pm 1.45 \mathrm{MPa}$ ) and $280^{\circ} \mathrm{C}$ (i.e. $38.29 \pm 0.43 \mathrm{MPa}$ ) is insignificant. Furthermore, the failure surfaces of the specimens after the tensile tests were examined visually. Figure 7 shows the failure modes of both cases. It can be seen that the specimens printed at an extruder temperature of $250{ }^{\circ} \mathrm{C}$ presented a SAT (Splitting, at grip/tab and top) type failure (Fig. 7a), while the $280{ }^{\circ} \mathrm{C}$ case (Fig. 7b) exhibited an AAT (Angled, at grip/tab and Top) failure as per the ASTM D3039 standard.

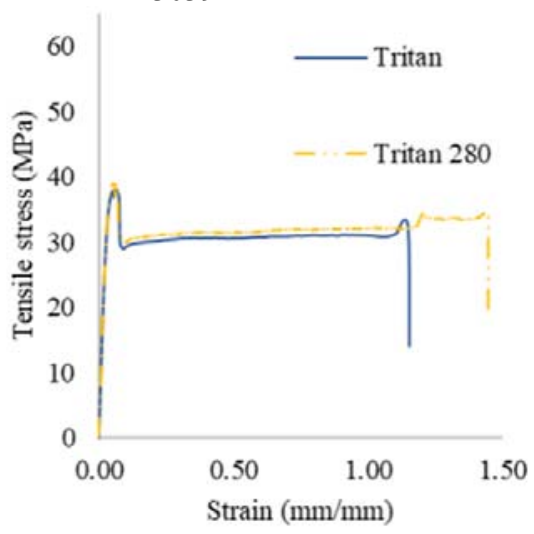

Fig. 6. Representative stress-strain curves for the $250^{\circ} \mathrm{C}$ and $280^{\circ} \mathrm{C}$ printed Tritan specimens 


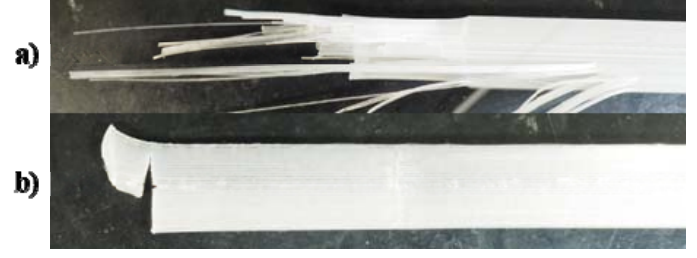

Fig. 7. Representative failures mode of Tritan tensile specimens printed at: a) $250^{\circ} \mathrm{C}$; b) Tritan at $280^{\circ} \mathrm{C}$

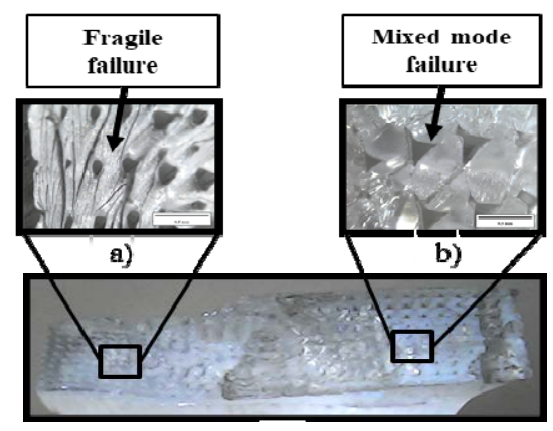

c)

Fig. 8. Cross-section of the Tritan printed at $280^{\circ} \mathrm{C}$, where a) fragile failure area; b) mixed mode failure area; c) the cross-section

For further clarification of the failure modes, an optical microscope was used to produce micrographs of the failure surfaces. Figure 8 shows the macro cross section view of the Tritan tensile specimen printed at $280^{\circ} \mathrm{C}$, as well as micrographs of two distinct failure zones. From figure $8 \mathrm{a}$, the micrograph from the leftmost side of the crosssection can be seen, where a smooth surface is visible, indicative of a fragile failure, as well as multiple crack fronts. From figure $8 \mathrm{~b}$ a micrograph of the zone opposite to the previously described can be observed, and a more ductile surface is visible, indicating a mixed mode failure.

Figure 9 shows a more detailed view of the cross-section micrographs. In figure 9a, inter filament voids are visible, as well as significant crack nucleation following these voids. Furthermore, a very homogeneous and smooth surface is visible where even the deposition layering sequence is not discernible. On the other hand, in figure $9 b$, a detailed view of the opposite end of the cross-section can be seen. Here, significant fracture surface differences can be observed. First, the layering sequence is clearly visible, along with the inter filament voids. However, crack nucleation and propagation is visible through the filaments with a ductile (wavy)/ fragile (smooth) transition zone. Moreover, despite these differences in failure mode, the ultimate failure load was not significantly affected by the extruder temperature. Thus, the $250^{\circ} \mathrm{C}$ temperature was chosen for the Tritan specimens.

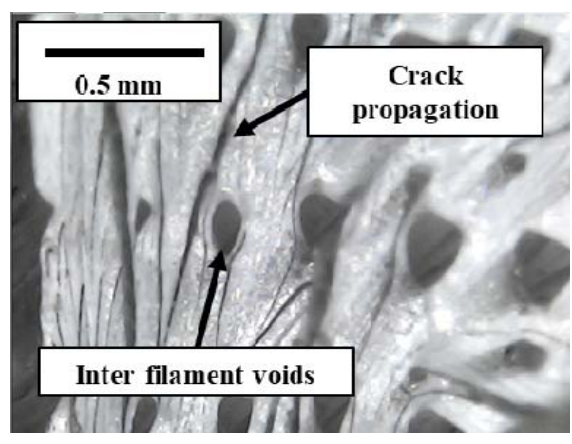

a)

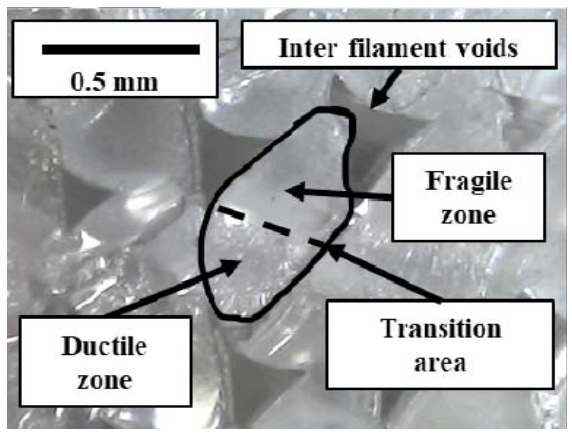

b)

Fig. 9. Cross-section micrograph of the Tritan printed tensile specimens at a $280^{\circ} \mathrm{C}$ extruder temperature

\section{RESULTS AND DISCUSSION}

\subsection{Tensile Tests}

Figure 10 shows representative tensile stress-strain curves obtained from the tensile tests of the FDM parts as a function of material. From the stress/strain curves the tensile data was calculated (tensile strength, Young's modulus and elongation at break), and the results are included in table 3. It can be seen that the material properties varied significantly as a function of the filament material. PLA had the highest tensile strength, with improvements of approx. $40 \%$ and $28 \%$ as compared to ABS and Tritan, respectively. The stiffness of the AM parts also varied as a function of filament material, with the highest value for the PLA and the lowest value for Tritan. Finally, the highest deformation was found for Tritan, while the lowest, as expected, was found for PLA.

Table 3. Tensile data for the materials studied

\begin{tabular}{|c|c|c|c|}
\hline Material & $\begin{array}{c}\text { Tensile } \\
\text { strength } \\
{[\mathbf{M P a}]}\end{array}$ & $\begin{array}{c}\text { Young's } \\
\text { modulus } \\
{[\mathbf{G P a}]}\end{array}$ & $\begin{array}{c}\text { Strain } \\
{[\%]}\end{array}$ \\
\hline PLA & $51.88 \pm 3.92$ & $3.72 \pm 0.17$ & $2.18 \pm 0.68$ \\
ABS & $31.03 \pm 0.11$ & $2.18 \pm 0.05$ & $24.98 \pm 0.1$ \\
Tritan & $37.79 \pm 1.45$ & $1.38 \pm 0.01$ & $104.14 \pm 30.98$ \\
\hline
\end{tabular}


a)

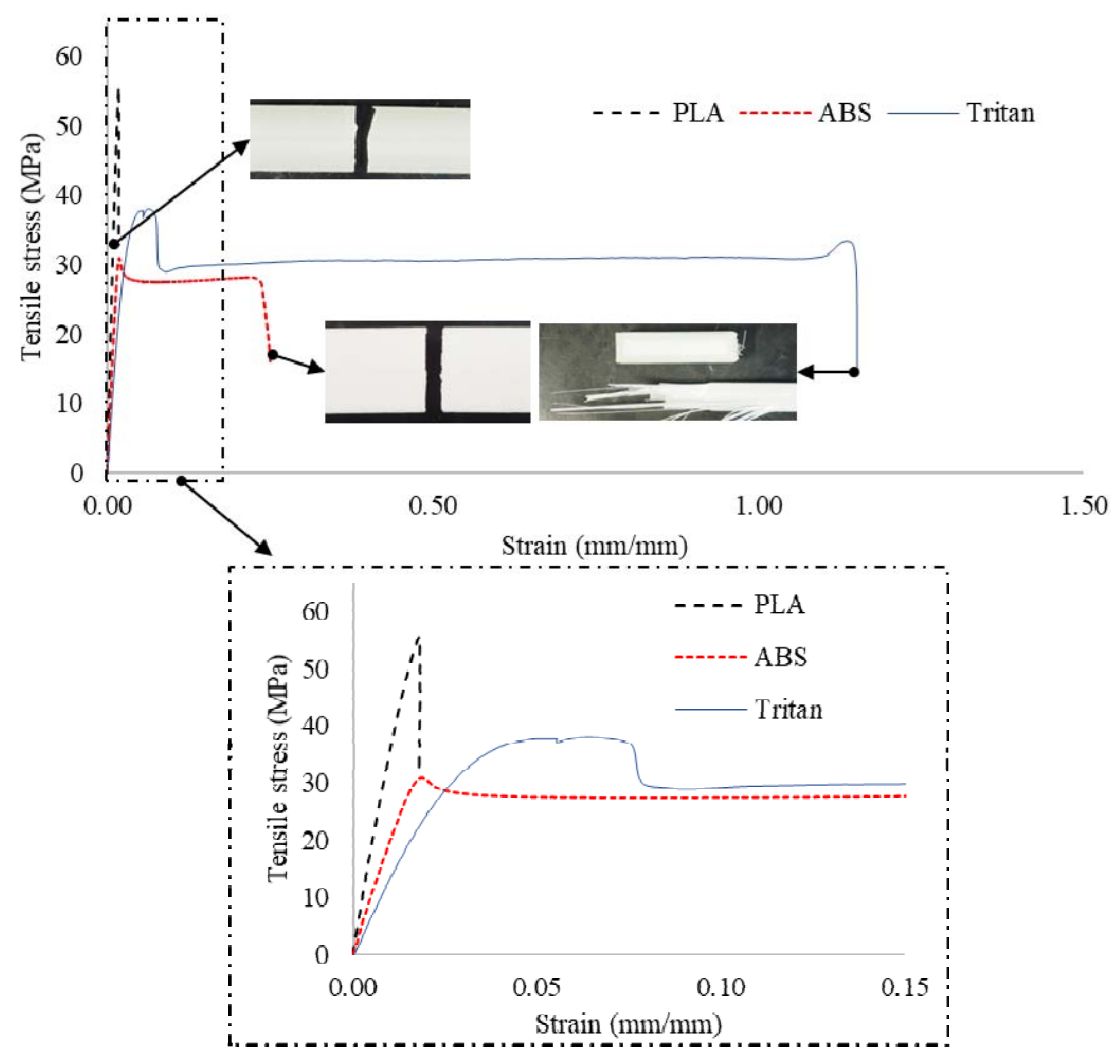

Fig. 10. Representative tensile stress-strain curves: a) as a function of material; b) Magnification of the linear part of the stress-strain curves

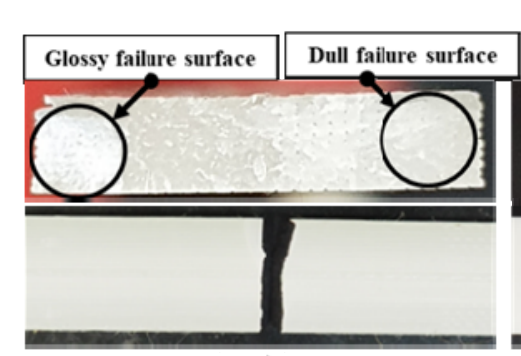

a)

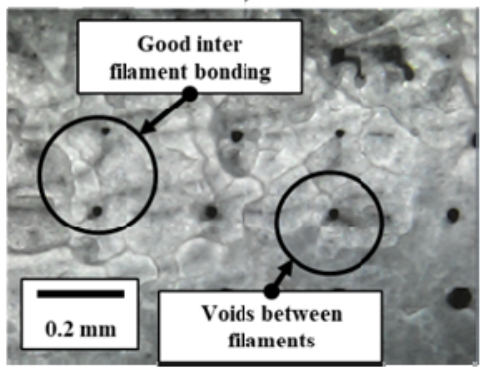

c)

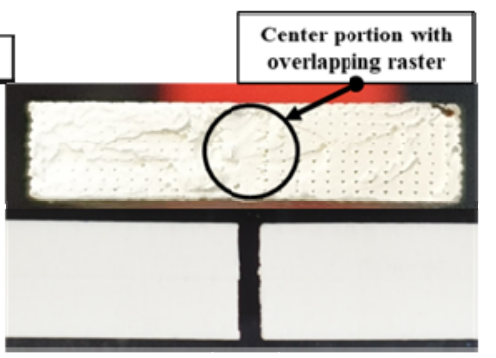

b)

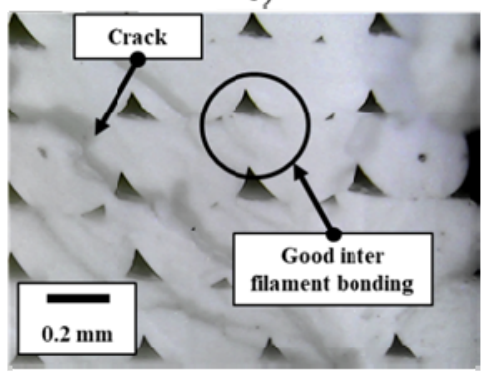

d)

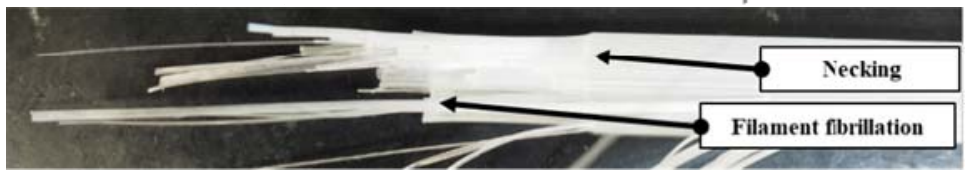

e)

Fig. 11. Representative tensile failures: a) cross-section of PLA specimen; b) cross-section of ABS specimen; c) PLA micrograph; d) ABS micrograph; e) Tritan fibrillation failure 
In figure 10 , it can be seen that the behaviour of the PLA material was predominantly brittle, while both ABS and Tritan exhibited a significantly more ductile behaviour. For a better visualisation of the initial slope, a magnified view of that particular area of the stress-strain curves can be seen in figure $10 \mathrm{~b}$ (the differences in stiffness as a function of material shown in table 3 can be seen more easily).

If the values in table 3 are compared to the supplier material properties (Table 1), little variation is found in terms of tensile strength (bellow 10\%) for PLA. However, a lower deformation was observed (approx. 28\%). Similar results were found for the ABS and Tritan, and the tensile strength exhibited little variation when compared to the supplier data. However, the elongation at break is higher for the ABS (by approx. 28\%), while for Tritan it is lower (by approx. 50\%), as compared to the supplier data. These variations are probably due to the different printing parameters used in this work.

The representative macro failure surfaces of the tested materials can be seen in figure 11. As specified by the ASTM D3039 standard, the PLA and ABS both presented AGM (Angled, gage and middle) failure, as seen in figures $11 \mathrm{a}$ and $\mathrm{b}$, respectively. For all specimens, the centre portion of the printed part presented very few to no internal voids, as seen in figure $11 \mathrm{~b}$. This is due to the slicing program that created an overlap in this portion of the sample. Magnified views of the failure surfaces taken with the aid of an optical microscope can be seen for PLA and ABS in figures $11 \mathrm{c}$ and $\mathrm{d}$, respectively. In figure $11 \mathrm{c}$, a very uniform failure surface is visible, with relatively small internal printing voids and essentially no layering. In other words, the material is very cohesive, with little to no visible deposition interphase. This is due to the temperature used during the printing process, which changes the void geometry [12]. This improvement in inter filament bonding is promoted by a higher diffusion time. The crack propagation was ductile in its progression, with smooth fragile patches in between crack fronts. Crack nucleation points were predictably close to the internal voids.

The ABS micrograph can be seen in figure 11d, where significant failure surface differences can be observed. For example, the layering sequence is clearly visible and uniform, as well as the printing voids. In addition, while the crack propagation here was also ductile in progression, it was more uneven in its topography. The macro failure mode of Tritan can be seen in figure 11e, and a SAT (Splitting, at grip/tab and top) failure mode is observable. This was described in this work as a fibre "fibrillation", as individual deposition fibres split and failed at the interphase during loading. Also, a "necking" front was observed during tensile testing, where significant Poisson deformation was visible, ending with the previously described fibrillation failure close to the top tab.

\subsection{Flexural Tests}

Figure 12 shows the representative flexural stress-strain curves of the AM parts as a function of material. From the stress/strain curves the flexural data was calculated and are seen in table 4.

Similar to the tensile properties, the flexural data varied significantly with the printed material. The PLA presented a brittle behaviour, while a more ductile behaviour was observed for the ABS and Tritan, as expected. It is important to note that the flexural tests of both the ABS and Tritan took a significant amount of time and were ultimately stopped due to specimen slippage.

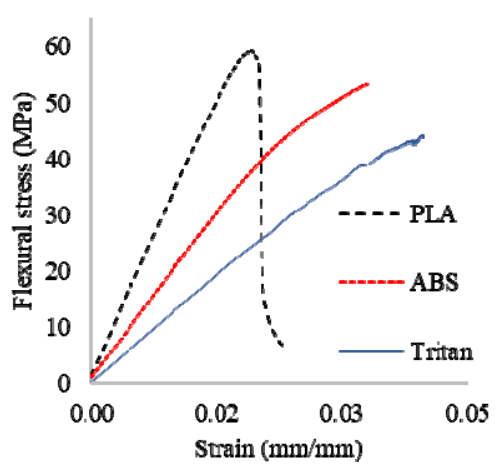

Fig. 12. Representative flexural stress-strain curves as a function of material

Table 4. Flexural data

\begin{tabular}{|c|c|c|}
\hline Material & $\begin{array}{c}\text { Flexural strength } \\
\text { [MPa] }\end{array}$ & $\begin{array}{c}\text { Flexural Modulus } \\
\text { [GPa] }\end{array}$ \\
\hline PLA & $60.85 \pm 1.57$ & $3.11 \pm 0.11$ \\
ABS & $53.32 \pm 1.54$ & $1.6 \pm 0.15$ \\
Tritan & $43.53 \pm 0.74$ & $1.08 \pm 0.08$ \\
\hline
\end{tabular}

An improvement in flexural strength of approx. 30\% and $22 \%$ was found when PLA was compared to Tritan and ABS, respectively. Similarly, in terms of flexural modulus, significant improvements were also observed (i.e. enhancements of approx. 50\% and 66\% when PLA was compared to ABS and Tritan). If the data obtained here is compared to the data provided by the supplier, a significant higher flexural modulus for the ABS can be seen (approx. 84\% higher). However, for the PLA and Tritan, lower values were obtained in the present study (approx. 12\% and 47\% lower than those provided by the supplier). The difference in values can be explained by the different layer thickness and filament orientation used in this study. It was shown in the literature that the layer thickness would directly impact void size and inter filament bonding [12], [16]. Also, the filament orientation impacts specimen rigidity [19]. This will be discussed further in the next section 3.3. 
Table 5. Tensile data

\begin{tabular}{|c|c|c|c|c|}
\hline Material & Parameters & $\begin{array}{c}\text { Tensile } \\
\text { strength } \\
\text { [MPa] }\end{array}$ & $\begin{array}{c}\text { Young's } \\
\text { [odulus } \\
\text { (GPa] }\end{array}$ & Ref. \\
\hline ABS & $0.2 \mathrm{~mm}$ Layer heigh $/ \pm 45^{\circ}$ Orientation / $100 \%$ Infill & 29.70 & 1.84 & [13] \\
\hline ABS & 0/90 Orientation / 100\% Infill & 27.60 & 1.74 & [13] \\
\hline ABS & $0.4 \mathrm{~mm}$ Layer height / 0/90 Orientation / 100\% Infill & 28.20 & 1.88 & [13] \\
\hline ABS & $\begin{array}{l}0.127 \mathrm{~mm} \text { Layer height } / \pm 45^{\circ} \text { Orientation / } 12 \text { Contour layers / } \\
100 \% \text { Infill }\end{array}$ & 30.66 & 1.80 & [14] \\
\hline $\mathrm{ABS}$ & $0.254 \mathrm{~mm}$ Layer height $/ 12.7 \mathrm{~mm} / \mathrm{s}$ Printing speed & 26.50 & 2.14 & [15] \\
\hline PLA & $0.30 \mathrm{~mm}$ Layer height / 85\% Infill & 37.90 & 0.36 & {$[8]$} \\
\hline PLA & $0 / 90$ Orientation/ $100 \%$ Infill & 60.40 & 3.48 & [13] \\
\hline PLA & $0.3 \mathrm{~mm}$ Layer height $/ \pm 45^{\circ}$ Orientation / $100 \%$ Infill & 48.50 & 3.34 & [13] \\
\hline PLA & $0.06 \mathrm{~mm}$ Layer height / Flat edge / $50 \mathrm{~mm} / \mathrm{s}$ Printing speed & 89.10 & 4.19 & [16] \\
\hline PLA & $0.24 \mathrm{~mm}$ Layer height / Flat edge / $50 \mathrm{~mm} / \mathrm{s}$ Printing speed & 72.30 & 3.77 & [16] \\
\hline PLA & $0.2 \mathrm{~mm}$ Layer height $/ 0^{\circ}$ Orientation $/ 3$ shell & 55.60 & 3.74 & [17] \\
\hline PLA & $0.15 \mathrm{~mm}$ Layer height $/ \pm 45^{\circ}$ Orientation / 2 Contour layers & 42.28 & 2.80 & [17] \\
\hline PLA & $0.2 \mathrm{~mm}$ Layer height $/ \pm 45^{\circ}$ Orientation $/ 60 \mathrm{~mm} / \mathrm{s}$ Printing speed & 61.42 & 3.96 & [18] \\
\hline
\end{tabular}

Table 6. Flexural data

\begin{tabular}{|c|c|c|c|c|}
\hline Material & Parameters & $\begin{array}{c}\text { Flexural } \\
\text { strength } \\
\text { [MPa] }\end{array}$ & $\begin{array}{c}\text { Flexural } \\
\text { modulus } \\
\text { [GPa] }\end{array}$ & Ref. \\
\hline $\mathrm{ABS}$ & $100 \%$ Infill $/+45 /-45$ Orientation & 42.69 & 0.50 & [19] \\
\hline ABS & $\begin{array}{l}0.10 \mathrm{~mm} \text { Layer height } / \pm 45^{\circ} \text { Orientation } / 60 \mathrm{~mm} / \mathrm{s} \text { Printing } \\
\text { speed }\end{array}$ & 48.38 & 1.50 & [20] \\
\hline PLA & $0.06 \mathrm{~mm}$ Layer height / Flat edge / $80 \mathrm{~mm} / \mathrm{s}$ Printing speed & 56.00 & 1.60 & [16] \\
\hline PLA & $0.06 \mathrm{~mm}$ Layer height / On-edge / $80 \mathrm{~mm} / \mathrm{s}$ Printing speed & 65.00 & 1.85 & [16] \\
\hline PLA & $0.12 \mathrm{~mm}$ Layer height / On-edge / $20 \mathrm{~mm} / \mathrm{s}$ Printing speed & 64.80 & 1.77 & [16] \\
\hline PLA & $0.27 \mathrm{~mm}$ Layer height / 78\% Infill & 60.90 & 2.47 & [8] \\
\hline PLA & $0.13 \mathrm{~mm}$ Layer height / 78\% Infill & 45.70 & 2.18 & [8] \\
\hline
\end{tabular}

\subsection{Comparative analysis}

Table 5 and 6 show a comparative analysis of the properties of the PLA and ABS which was performed in order to evaluate the impact of the methodology and the results obtained in the present work using relevant specialised literature [13]-[20]. It can be seen that the values found in the literature varied for the same material. For instance, the tensile strength found in this study for the ABS (i.e. $31.03 \pm 0.11$ ) were close to the values found in some studies [13, 14] and superior to values found in [15]. The difference in values as compared to the study of Rodríguez et al. [15] may be explained by the fact that the larger layer height value used in the present study promoted fewer internal voids and consequently improved tensile properties.

The printing speed is also a factor that influences the tensile properties of the printed parts. It was shown in the literature that a slower printing speed promotes a better molecular alignment and allows each layer to cool down before the next one is printed, and thus inter filament bonding is improved.

The tensile strength of the PLA printed parts found in the literature varied from approx. 37 to 89 MPa [8], [13], [16]-[18]. The layer thickness of the printed parts varied between 0.06 and $0.3 \mathrm{~mm}$, which can be the reason behind the superior variability in the values found for this material as compared to ABS. For example, Chacón et. al. [16] studied the effect of the printing parameters (i.e. layer thickness, printing orientation and speed) on the material properties of PLA. It was found that a lower layer height along with an average printing speed and flat orientation were the best parameter combination for optimum tensile properties. The smaller layers will result in fewer voids, while also greatly increasing the printing time. For example, an increase in printing time of approx. $255 \%$ was reported when the $0.06 \mathrm{~mm}$ layer height case is compared to the $0.27 \mathrm{~mm}$ case [16]. However, the parameters used in this work for the PLA achieved a good compromise between the printing time ( $\sim 35 \mathrm{~min}$ per tensile sample) and the mechanical properties. Finally, the values for the 
Young's modulus found in this work for ABS and PLA are in line with those found in the literature.

The same as the tensile properties, the flexural characteristics of the material were also found to be dependent on the printing parameters (Table 6). For ABS, the flexural strength found in this study had a higher value when compared to those found in the literature. This is mainly due to the raster orientation used, where the totally aligned filaments provide better resistance to tensile loads, consequently increasing the flexural strength and modulus [19]. Regarding the PLA, little variation was found when the flexural strength found in this work is compared to the available literature. However, the flexural modulus of PLA found in this study is approx. $68 \%$ higher than the value found in [16]. On the other hand, the values obtained in this study are close to those obtained in the flat edge configuration by Chacón et al. [16]. It can be concluded that the print orientation has a higher impact on the flexural properties than the layer thickness or printing speed.

\section{CONCLUSIONS}

In this study, the influence of the material and the 3D printing parameters on the mechanical properties of additive manufactured thermoplastic parts was investigated. The results show that the type of filaments had the greatest influence on the mechanical properties of the AM parts. Among the tested materials, the one with the highest tensile strength was the PLA (51.88 MPa), followed by the Tritan (37.79 $\mathrm{MPa})$ and finally, the ABS (31.03 MPa). In terms of stiffness, PLA is the best material, followed by ABS and Tritan which had the lowest value. Finally, Tritan manifested the highest deformation, while PLA displayed the lowest deformation capacity. Regarding the flexural properties, PLA presented the best properties, followed by ABS and Tritan. The mechanical properties of the printed parts also depend on the printing parameters. The printing parameters used in this work achieved a good compromise between the printing time and the mechanical properties of the AM parts. The mechanical properties of the AM materials were optimised in order to stimulate their use in new applications in the industry.

\section{ACKNOWLEDGEMENTS}

Authors would like to acknowledge the support of the Brazilian Research Agencies CNPq and FAPERJ.

\section{REFERENCES}

[1] *** ASTM Standard F2792, Standard terminology for additive manufacturing technologies, vol. 2012, ASTM International, West Conshohocken, Pa, USA, 2012

[2] Cavalcanti D. K. K., Banea M. D., de Queiroz H. F. M., Mechanical characterization of bonded joints of additive manufactured adherends, Annals of Dunarea de Jos University of Galati Fascicle XII, Welding Equipment and Technology, vol. 29,
2019, pp. 27-33.

[3] Popescu D., Zapciu A., Amza C., Baciu F., Marinescu R., FDM process parameters influence over the mechanical properties of polymer specimens: A review, Polymer Testing 69, 2018, pp. 157-166.

[4] Solomon A., Rosenthal Y., Ashkenazi D., Stern A., Structure and mechanical behavior of additive manufactured fused deposition modeling ABS, Annals of "Dunarea de Jos" University of Galati. Fascicle XII, Welding Equipment and Technology 29, 2018, pp. $47-56$

[5] Ngo T. D., Kashani A., Imbalzano G., Nguyen K. T. Q., Hui D., Additive manufacturing (3D printing): A review of materials, methods, applications and challenges, Composites Part B Engineering. vol. 143, 2018, pp. 172-196.

[6] Sood A. K., Ohdar R. K., Mahapatra S. S., Parametric appraisal of mechanical property of fused deposition modelling processed parts, Materials \& Design, vol. 31(1), 2010, pp. 287-295.

[7] Carrasco F., Pagès P., Gámez-Pérez J., Santana O. O. Maspoch M. L., Processing of poly(lactic acid): characterization of chemical structure, thermal stability and mechanical properties, Polymer Degradation and Stability, vol. 95, 2010, pp. 116-125.

[8] Camargo J. C., Machado A. R., Almeida E. C., Silva E. F. M. S., Mechanical properties of PLA-graphene filament for FDM $3 D$ printing, The International Journal of Advanced Manufacturing Technology, vol. 103(5), 2019, pp. 2423-2443.

[9] Harris M., Potgieter J., Archer R., Arif K. M. E., Effect of Material and Process Specific Factors on the Strength of Printed Parts in Fused Filament Fabrication: A Review of Recent Developments, Materials, vol. 12(10), 2019, pp. 1664.

[10] Wang L., Sanders J. E., Gardner D. J., Han Y., Effect of fused deposition modeling process parameters on the mechanical properties of a filled polypropylene, Progress in Additive Manufacturing. vol. 3(4), 2018, pp. 205-214.

[11] Aliheidari N., Tripuraneni R., Hohimer C., Christ J., Ameli A., Nadimpalli S., The impact of nozzle and bed temperatures on the fracture resistance of FDM printed materials, Smart Structures and Materials + Nondestructive Evaluation and Health Monitoring, vol. 10165. 2017, pp. 1016512.

[12] Kuznetsov V. E., Solonin A. N., Tavitov A. G., Urzhumtsev, O. D., Vakulik A., Increasing of strength of FDM (FFF) $3 D$ printed parts by influencing on temperature-related parameters of the process, Rapid Prototyping Journal, 2018, pp. 1-32.

[13] Tymrak B. M., Kreiger M., Pearce J. M., Mechanical properties of components fabricated with open-source 3-D printers under realistic environmental conditions, Materials \& Design, vol. 58, 2014, pp. 242-246.

[14] Schmitt M., Mehta R. M., Kim I. Y., Additive manufacturing infill optimization for automotive 3D-printed ABS components, Rapid Prototyping Journal, vol. 26, 2020, pp 89-99.

[15] Rodríguez J. F., Thomas J. P., Renaud J. E., Mechanical behavior of acrylonitrile butadiene styrene (ABS) fused deposition materials. Experimental investigation, Rapid Prototyping Journal, vol. 7, 2001, pp. 148-459.

[16] Chacón J. M., Caminero M. A., García-Plaza E., Núnez P. J., Additive manufacturing of PLA structures using fused deposition modelling: Effect of process parameters on mechanical properties and their optimal selection, Materials \& Design, vol. 124, 2017, pp. 143-157.

[17] Pei E., Lanzotti A., Grasso M., Staiano G., Martorelli M., The impact of process parameters on mechanical properties of parts fabricated in PLA with an open-source 3-D printer Rapid Prototyping Journal, vol. 21, 2015, pp. 604-617.

[18] Wang K., Li S., Rao Y., Wu Y., Peng Y., Yao, S., Zhang, H., Ahzi, S., Measurements of the mechanical response of unidirectional 3D-printed PLA, Materials \& Design, vol. 123, 2017, pp. 154-164.

[19] Weng Z., Wang J., Senthil T., Wu L., Mechanical and thermal properties of ABS/montmorillonite nanocomposites for fused deposition modeling $3 D$ printing, Materials \& Design, vol. 102, 2016, pp. 276-283.

[20] Wang K., Li S., Rao Y., Wu Y., Peng Y., Yao S., Zhang H. Ahzi S., Flexure behaviors of ABS-based composites containing carbon and Kevlar fibers by material extrusion $3 D$ printing, Polymers, vol. 11, 2019, pp. 1-12. 